University of South Carolina

Scholar Commons

$5-15-2002$

\title{
Nanofatigue Studies of Ultrathin Hard Carbon Overcoats Used in Magnetic Storage Devices
}

\author{
Xiaodong Li \\ University of South Carolina - Columbia, lixiao@cec.sc.edu \\ Bharat Bhushan
}

Follow this and additional works at: https://scholarcommons.sc.edu/emec_facpub

Part of the Mechanical Engineering Commons, and the Nanoscience and Nanotechnology Commons

\section{Publication Info}

Published in Journal of Applied Physics, Volume 91, Issue 10, 2002, pages 8334-8336.

Copyright American Institute of Physics, 2002.

$\mathrm{Li}, \mathrm{X} .$, \& Bhushan, B. (2002). Nanofatigue Studies of Ultra-Thin Hard Carbon Overcoats Used in Magnetic Storage Devices. Journal of Applied Physics, 91(10): 8334-8336.

http://dx.doi.org/10.1063/1.1452699

This Article is brought to you by the Mechanical Engineering, Department of at Scholar Commons. It has been accepted for inclusion in Faculty Publications by an authorized administrator of Scholar Commons. For more information, please contact digres@mailbox.sc.edu. 


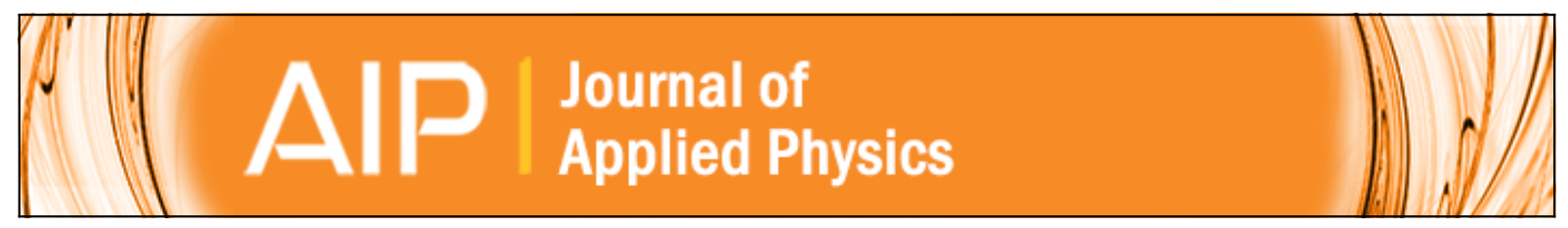

\section{Nanofatigue studies of ultrathin hard carbon overcoats used in magnetic storage devices}

Xiaodong Li and Bharat Bhushan

Citation: Journal of Applied Physics 91, 8334 (2002); doi: 10.1063/1.1452699

View online: http://dx.doi.org/10.1063/1.1452699

View Table of Contents: http://scitation.aip.org/content/aip/journal/jap/91/10?ver=pdfcov

Published by the AIP Publishing

\section{Articles you may be interested in}

Studies of pure and nitrogen-incorporated hydrogenated amorphous carbon thin films and their possible application for amorphous silicon solar cells

J. Appl. Phys. 111, 014908 (2012); 10.1063/1.3675164

Nanoscale fatigue and fracture toughness measurements of multilayered thin film structures for digital micromirror devices

J. Vac. Sci. Technol. A 22, 1397 (2004); 10.1116/1.1738659

Coverage and properties of a- SiN $x$ hard disk overcoat

J. Appl. Phys. 93, 8704 (2003); 10.1063/1.1543136

Substrate/layer interface of amorphous-carbon hard coatings

J. Appl. Phys. 88, 1861 (2000); 10.1063/1.1305553

Mechanical and fracture toughness studies of amorphous $\mathrm{SiC}-\mathrm{N}$ hard coatings using nanoindentation J. Vac. Sci. Technol. A 15, 963 (1997); 10.1116/1.580788

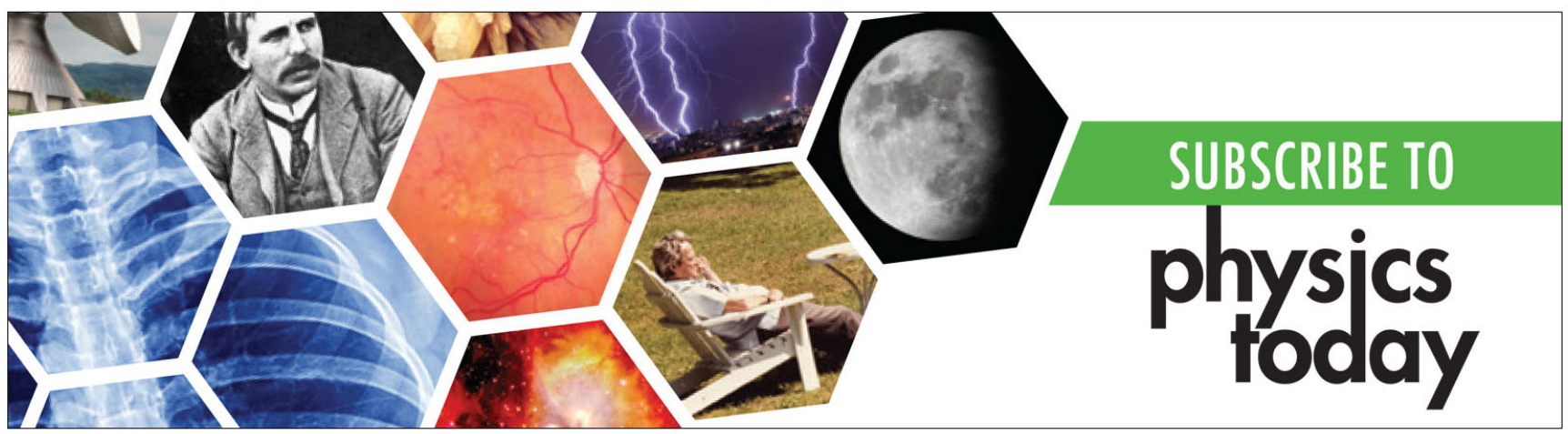




\title{
Nanofatigue studies of ultrathin hard carbon overcoats used in magnetic storage devices
}

\author{
Xiaodong Li and Bharat Bhushan ${ }^{\text {a) }}$ \\ Nanotribology Laboratory for Information Storage and MEMS/NEMS, Department of Mechanical \\ Engineering, The Ohio State University, 206 West 18th Avenue, Columbus, Ohio 43210-1107
}

A technique to perform nanofatigue experiments was developed. This technique utilizes a depth-sensing nanoindenter with harmonic force. The nanofatigue behavior of $20 \mathrm{~nm}$ thick amorphous carbon coatings was studied. The contact stiffness was monitored continuously throughout the test. The abrupt decrease in the contact stiffness indicates fatigue damage has occurred. The critical load amplitude, below which no fatigue damage occurs, was identified. It was found that the filtered cathodic arc coating exhibits longer fatigue life than a direct ion beam coating. Failure mechanisms of the coatings during fatigue are also discussed in conjunction with the hardness, elastic modulus, and fracture toughness, as well as deposition processes. The dynamic nanoindentation fatigue test used in this study can be satisfactorily used to simulate and study damage at the head-disk interface. (C) 2002 American Institute of Physics.

[DOI: $10.1063 / 1.1452699$ ]

\section{INTRODUCTION}

Amorphous carbon coatings, often called diamond-like carbon (DLC) coatings, are employed as overcoats to protect heads and media in magnetic storage devices. These overcoats have to be thin $(2-20 \mathrm{~nm})$ in order to minimize loss of the read back signal amplitude. ${ }^{1}$ Frequent, high magnitude impacts that occur at the head-disk interface during contact start/stop or load/unload as well as slider flying cause fatal damage in the hard disk drive. To evaluate the resistance to this impact the fatigue properties of the coatings must be measured. Nanoscale fatigue has rarely been studied in the past because of the lack of specialized instruments. A recently developed technique, continuous stiffness measurement $(\mathrm{CSM}){ }^{2}$ offers a significant improvement in nanoindentation testing. Load cycles used in the CSM can be used to perform fatigue tests at the nanoscale. The fatigue behavior of coatings can be studied by monitoring the change in contact stiffness since the contact stiffness is sensitive to the formation of damage. Intensive research has been done on measurements of the hardness, elastic modulus, fracture toughness, and tribological properties of ultrathin DLC overcoats, ${ }^{3-6}$ however, very little is understood with regard to their fatigue properties. The objective of this study was to develop a technique with which to perform nanofatigue experiments. In this article we present an attempt to measure nanofatigue properties of $20 \mathrm{~nm}$ thick DLC overcoats.

\section{EXPERIMENT}

DLC coatings of $20 \mathrm{~nm}$ thickness were deposited on polished (100) single-crystal silicon substrates [root mean square (rms) surface roughness of 2-3 nm] by direct ion beam (IB) and filtered carthodic arc (FCA) processes. ${ }^{3-6}$ Nanofatigue experiments were carried out using a NanoIndenter II ${ }^{\circledR}$ (MTS Systems Corp.) equipped with the CSM

${ }^{a)}$ Electronic mail: bhushan.2@osu.edu option. This instrument monitors and records the dynamic load and displacement of the indenter during indentation with a force resolution of about $75 \mathrm{nN}$ and displacement resolution of about $0.1 \mathrm{~nm}$. A diamond conical indenter with a radius of $1 \mu \mathrm{m}$ and an angle of $60^{\circ}$ was used. The CSM technique was described in detail in Ref. 2. Briefly, a harmonic force is added to the nominally increasing load, $P$, on the indenter. The displacement response of the indenter at the excitation frequency and the phase angle between the two are measured continuously as a function of the depth. Solving
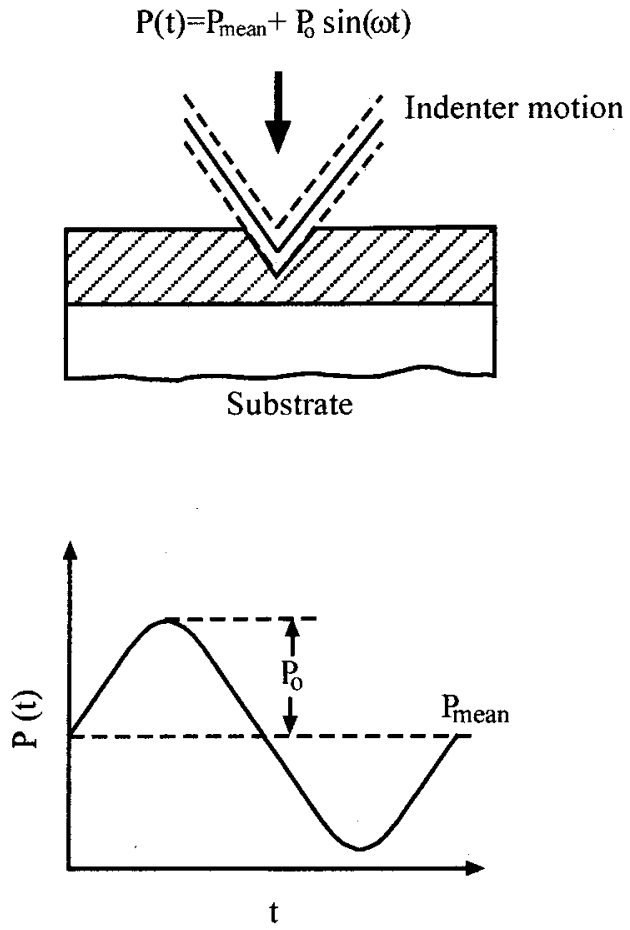

FIG. 1. Schematic of a fatigue test made on a thin film/substrate system by the CSM technique. 


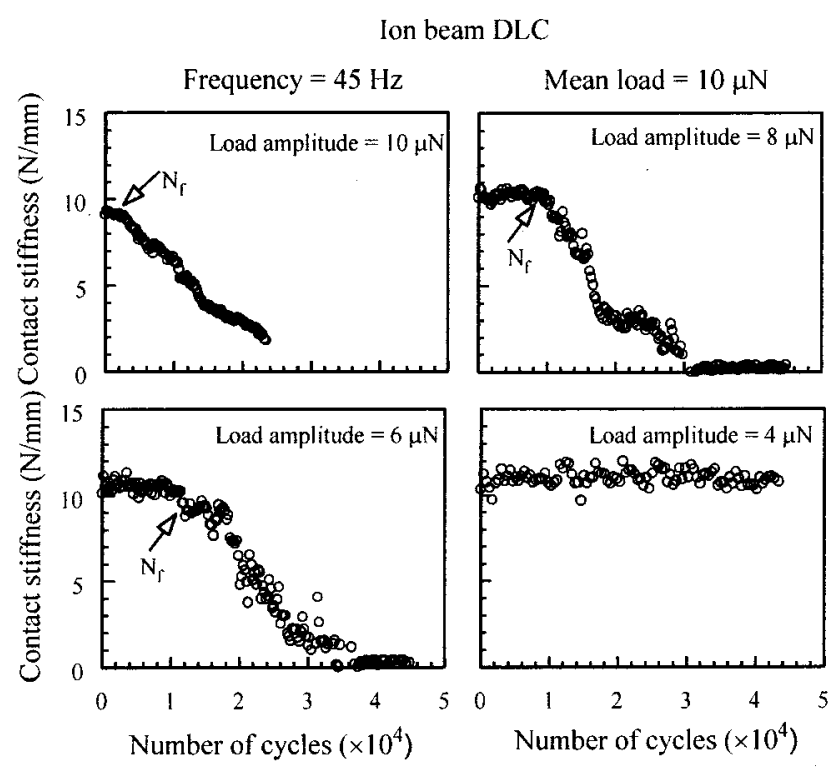

(a)

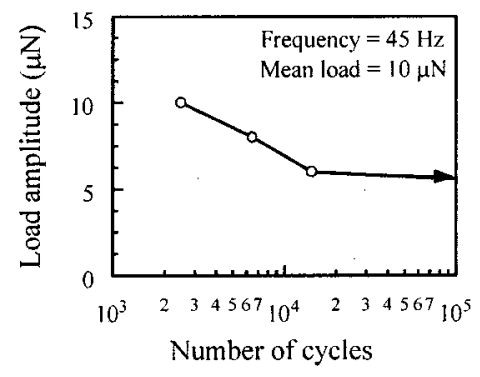

(b)

FIG. 2. (a) Contact stiffness as a function of the number of cycles for a 20 $\mathrm{nm}$ thick IB coating on a $\mathrm{Si}(100)$ substrate cyclically deformed by various oscillation load amplitudes with a mean load of $10 \mu \mathrm{N}$ at a frequency of 45 Hz. (b) Plot of the load amplitude vs $N_{f}$.

for the in-phase and out-of-phase portions of the response results in a explicit determination of the contact stiffness as a continuous function of the depth. The CSM technique provides load cycles of sinusoidal shape at high frequencies that can be used to perform nanoscale fatigue tests. The fatigue

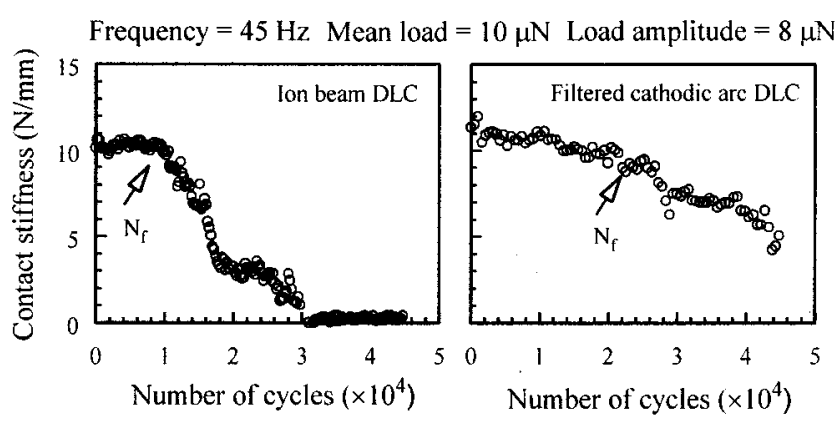

FIG. 3. Contact stiffness as a function of the number of cycles for $20 \mathrm{~nm}$ thick IB and FCA coatings on $\mathrm{Si}(100)$ substrates cyclically deformed by an oscillation load amplitude of $8 \mu \mathrm{N}$ with a mean load of $10 \mu \mathrm{N}$ at a frequency of $45 \mathrm{~Hz}$.

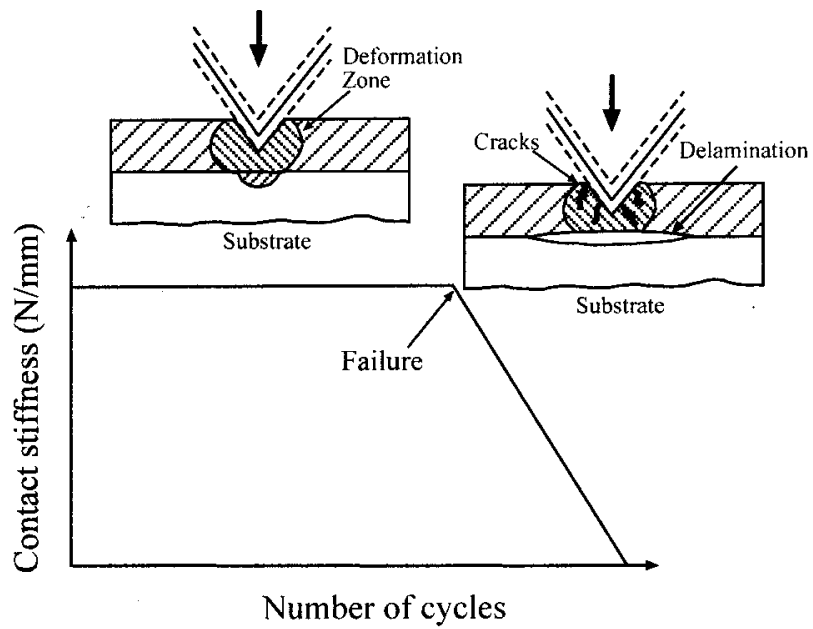

FIG. 4. Schematic of fatigue damage mechanisms of the coating/substrate system.

behavior of coatings can be studied by monitoring the change in contact stiffness since the contact stiffness is sensitive to the formation of damage. To obtain the fatigue deformation and damage, large amplitude oscillations were used. The numbers of cycles were determined from the time elapsed. Figure 1 shows a schematic of a fatigue test on a thin film/substrate system using the CSM technique. Load cycles are applied to the coating, resulting in cyclic stress. $P$ is the cyclic load, $P_{\text {mean }}$ the mean load, $P_{\text {os }}$ the oscillation load amplitude, and $\omega$ the oscillation frequency. All fatigue tests were conducted at an excitation frequency of $45 \mathrm{~Hz}$.

\section{RESULTS AND DISCUSSION}

Figure 2(a) shows the contact stiffness as a function of the number of cycles for a $20 \mathrm{~nm}$ thick IB coating on a $\mathrm{Si}(100)$ substrate cyclically deformed by various oscillation load amplitudes with a mean load of $10 \mu \mathrm{N}$ at a frequency of $45 \mathrm{~Hz}$. At $4 \mu \mathrm{N}$ load amplitude, no change in the contact stiffness was found. This indicates that $4 \mu \mathrm{N}$ load amplitude is not high enough to damage the coating. At $6 \mu \mathrm{N}$ load amplitude, an abrupt decrease in the contact stiffness was found at $0.8 \times 10^{4}$ cycles, indicating that fatigue damage has occurred. With an increase in the load amplitude, the number of cycles to failure, $N_{f}$, decreases. Load amplitude versus $N_{f}$ is plotted in Fig. 2(b). The critical load amplitude, below which no fatigue damage occurs, was identified. This critical load amplitude together with the mean load is of critical importance to the design of magnetic storage devices.

The nanofatigue properties of $20 \mathrm{~nm}$ thick IB and FCA coatings are compared in Fig. 3. The $N_{f}$ of the FCA coating is two times longer than that of the IB coating. In addition, after the $N_{f}$, the contact stiffness of the FCA coating shows a slower decrease than the IB coating. This indicates that after the $N_{f}$, the FCA coating had less damage than the IB coating.

The nanofatigue damage mechanisms of the coating/ substrate system studied are believed to be those illustrated in Fig. 4. Before $N_{f}$, no cracking or delamination occurs, only elastic-plastic deformation that does not change the 
TABLE I. Calculated values of the mean contact pressure and normal approach at a normal load of $18 \mu \mathrm{N}$ (mean load $=10 \mu \mathrm{N}$, load amplitude $=8 \mu \mathrm{N})$ using Hertz analysis and the mechanical properties and fatigue life of the IB and FCA coatings.

\begin{tabular}{lccccc}
\hline \hline Coating & $\begin{array}{c}\text { Mean contact } \\
\text { pressure }^{\mathrm{a}} \\
(\mathrm{GPa})\end{array}$ & $\begin{array}{c}\text { Normal } \\
\text { approach }^{\mathrm{b}} \\
(\mathrm{nm})\end{array}$ & $\begin{array}{c}\text { Hardness }^{\mathrm{d}} \\
(\mathrm{GPa})\end{array}$ & $\begin{array}{c}\text { Elastic } \\
\text { modulus }^{\mathrm{d}} \\
(\mathrm{GPa})\end{array}$ & $\begin{array}{c}\text { Fracture } \\
\text { toughness }^{\mathrm{e}} \\
\left(\mathrm{MPa} \mathrm{m}^{1 / 2}\right)\end{array}$ \\
\hline IB & 2.8 & 2.4 & 19 & 140 & 4.3 \\
FCA & 4.4 & 1.5 & 24 & 280 & $\begin{array}{c}N_{f}^{c} \\
\left(\times 10^{4}\right)\end{array}$ \\
\hline \hline
\end{tabular}

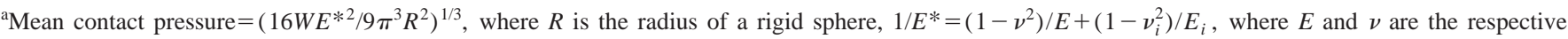
elastic modulus and Poisson ratio of the coating and $E_{i}$ and $\nu_{i}$ are the same quantities as the preceding but for the indenter. $W$ is the normal load. The Poisson ratio of DLC is assumed to be 0.25 (after Ref. 6) and the indenter is assumed to be rigid.

${ }^{\mathrm{b}}$ Normal approach $=\left(9 W^{2} / 16 R E^{* 2}\right)^{1 / 3}$.

${ }^{\mathrm{c}} N_{f}$ was obtained from Fig. 3 at a mean load of $10 \mu \mathrm{N}$ and a load amplitude of $8 \mu \mathrm{N}$.

${ }^{\mathrm{d}}$ References 3-5.

${ }^{\mathrm{e}}$ Reference 6.

contact stiffness value. At this stage, the energy accumulated by cyclical deformation is not high enough to form cracks or cause delamination. At and after $N_{f}$, cracks form and/or delamination occurs, causing a decrease in the contact stiffness. The formation of fatigue cracks depends upon the hardness and fracture toughness. It is more difficult for cracks to form and propagate in the coating that has greater strength and fracture toughness. Table I shows the fatigue properties together with the mean contact pressure, normal approach and other mechanical properties of the IB and FCA coatings. We note that higher hardness and fracture toughness lead to longer fatigue life. The mechanical properties of DLC coatings are controlled by the $s p^{3}$-to-s $s p^{2}$ ratio. The $s p^{3}$-bonded carbon exhibits the outstanding properties of diamond. ${ }^{3}$ Higher deposition kinetic energy will result in a larger fraction of $s p^{3}$-bonded carbon in an amorphous network. Thus, the higher kinetic energy for the FCA could be responsible for its better carbon structure and higher mechanical properties. In addition, greater adhesion strength between the FCA coating and the substrate ${ }^{4}$ makes the FCA coating more difficult to delaminate from the substrate. After the $N_{f}$, the cracks in the coating and at the coating/substrate interface propagate more slowly in the FCA coating because of its high hardness and fracture toughness and adhesion strength, thereby leading to a slower decrease in contact stiffness.

\section{CONCLUSIONS}

Load cycles used in the CSM were successfully used to study the nanofatigue properties of $20 \mathrm{~nm}$ thick DLC overcoats. The fatigue behavior of the coatings was monitored by the change in contact stiffness. The FCA coating exhibits longer fatigue life than the IB coating. Higher hardness, fracture toughness and adhesion strength are responsible for the longer fatigue life. The FCA coating appears to be the more promising for applications.

${ }^{1}$ B. Bhushan, Tribology and Mechanics of Magnetic Storage Devices, 2nd ed. (Springer, New York, 1996).

${ }^{2} \mathrm{X}$. Li and B. Bhushan, Mater. Charact. (in press).

${ }^{3}$ B. Bhushan, Diamond Relat. Mater. 8, 1985 (1999).

${ }^{4}$ X. Li and B. Bhushan, J. Mater. Res. 14, 2328 (1999).

${ }^{5}$ X. Li and B. Bhushan, Z. Metallkd. 90, 820 (1999).

${ }^{6}$ X. Li and B. Bhushan, Thin Solid Films 355-356, 330 (1999). 